\title{
Assessment of different voltage sags on performance of induction motors operated with shunt FACTS
}

\begin{abstract}
Shunt FACTS devices are prevalent in industrial application of induction motors. These equipments are effective to compensate disturbances and increase motor speeding up. Whereas voltage sags is one of the most conventional power quality contexts in power systems, the performances of the induction motor under symmetrical and unsymmetrical voltage sags are investigated in this paper. The results prove that STATCOM is more effectual than SVC for reduction of transients and refinement the voltage profile. Between different types of unsymmetrical voltage sags, one type has maximum effect on variation range of voltage overshoot and voltage undershoot and two types have lowest influence on variation range of voltage overshoot and voltage undershoot.
\end{abstract}

Keyword: Induction motor; SVC; STATCOM; Power quality; Symmetrical and unsymmetrical voltage sags 